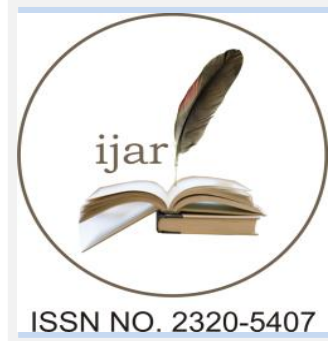

ISSN NO. 2320-5407
Journal Homepage: - $\underline{w w w . j o u r n a l i j a r . c o m}$

INTERNATIONAL JOURNAL OF

ADVANCED RESEARCH (IJAR)

Article DOI: $10.21474 /$ IJAR01/4328

DOI URL: http://dx.doi.org/10.21474/IJAR01/4328

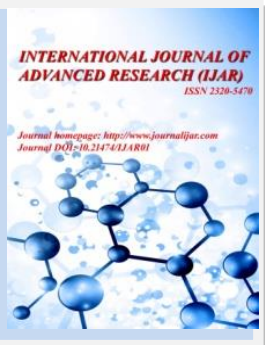

RESEARCH ARTICLE

\section{A COMPARATIVE STUDY ON QUANTITATIVE PHYTOCHEMICAL ANALYSIS AND IN VITRO FREE RADICAL SCAVENGING ACTIVITYOF VARIOUS SOLVENT EXTRACTS OF TETRACERA AKARA (BURM. F.) MERR., AN ETHNOMEDICINAL PLANT USED BY KANI TRIBE OF KERALA.}

Ragesh R Nair, S R Suja*, A L Aneeshkumar, V Vilash and S Rajasekharan.

Ethnomedicine and Ethnopharmacology Division, Jawaharlal Nehru Tropical Botanic

Garden and Research Institute, Palode, Thiruvananthapuram 695 562, Kerala, India.

\section{Manuscript Info}

Manuscript History

Received: 26 March 2017

Final Accepted: 31 April 2017

Published: May 2017

Key words:-

Tetracera akara, Kani tribe, Free radical scavenging, DPPH etc.
Abstract

Tetracera akara (Burm. f.) Merr. (Dellineaceae) is a woody climber distributed in Indo-Malayan archipelago and in India, it is found in the Western Ghats region of Kerala and Tamil Nadu. The root of T. akara is used by the Kani tribe of Kerala, India to cure various liver ailments like jaundice, inflammatory conditions, fever and also to enhance the immunity in children. The present study was aimed to scientifically validate the free radical scavenging potential of different solvent extracts of T. akara roots with different in vitro assays and also to estimate the total phenolic, flavonoid and condensed tannin contents. A significantly higher total poly phenolic content was estimated in the ethanolic fraction of root of T. akara. The aqueous extracts possess significantly higher phenol and flavonoid content. The ethanolic fraction of T. akara root exhibited $86 \%$ inhibition against DPPH radicals at $320 \mu \mathrm{g} / \mathrm{ml}$ concentration. Hexane and chloroform fractions showed comparatively less DPPH radical activity. In nitric oxide radical scavenging assay, all the extracts except hexane fraction showed potent activity against the free radicals and in superoxide radical scavenging assay the maximum activity was exhibited by the ethanolic fraction when compared to the standard ascorbic acid. In the present study, the antioxidant potential and free radical scavenging effects of $T$. akara may be attributed to the high polyphenolic content.

\title{
Introduction:-
}

Free radicals are chemical species with one or more unpaired electrons in the outer ring with very short half-life, high reactivity and damaging macromolecules like proteins, DNA and lipids. In normal physiological conditions the scavenging of free radicals is carried out by antioxidant defense mechanism of the body. Sometimes, excessive free radicals are formed and the antioxidant system within cannot cope with the situation leading to a condition known as oxidative stress. Several endogenous causes like mitochondrial electron transport chain, auto-oxidation of amino acids, respiratory burst of phagocytes and beta oxidation of fat in peroxisomes and exogenous factors like chemicals, ionizing radiations, cigarette smoke and vehicle exhaust leads to the formation of free radicals. The Free radicals formed in vivo are highly reactive transient chemical species potentially damaging tissues and implicated in the pathogenesis of

Corresponding Author:- S R Suja.

Address:-Ethnomedicine and Ethnopharmacology Division, Jawaharlal Nehru Tropical Botanic Garden and Research Institute, Palode, Thiruvananthapuram 695 562, Kerala, India. 
a variety of disorders, including degenerative disorders of the central nervous system such as Alzheimer's disease, cancer, atherosclerosis, diabetes mellitus, hypertension, AIDS and aging (Halliwell and Gutteridge, 1998).

Antioxidant refers to a compound that can delay or inhibit the oxidation of lipids or other biomolecules by inhibiting the initiation or propagation of oxidative chain reactions and thus prevent or repair damage done to the body's cells by free radicals. They act by one or more of the following mechanisms like reducing activity, free radical-scavenging, potential complexing of pro-oxidant metals and quenching of singlet oxygen. Recent studies have investigated the potential of plant products as antioxidants against various diseases induced by free radicals and it has been determined that the antioxidant effect of plant products is mainly attributed to polyphenolic compounds, such as flavonoids, phenolic acids and tannins in it. (Ebrahimzadehb et al., 2009). Dietary polyphenols are natural antioxidants present in plants, conferring protection against free radicals when consumed and thus are important in maintaining good health (Nabavi et al., 2008). Synthetic antioxidants such as butylated hydroxytoluene (BHT), butylated hydroxyanisole (BHA) and tert-butylated hydroxyquinone are available, but have deleterious side effects and are promoters of carcinogenesis (Blokhina et al., 2003). Therefore, the importance of searching for and exploiting natural antioxidants has increased greatly in present years. In spite of tremendous development in the field of allopathic medicines during the recent years, plants still remain one of the major sources of drugs in modern as well as traditional system of medicine and playing a vital role on the health and healing. Traditional medicinal plants are now moving from fringe to main stream as people are becoming more aware of therapeutic interventions of these medicinal plant resources and their products in maintaining health and preventing diseases with an eco-friendly touch.

Tetracera akara (Burm. f.) Merr. belongs to the family Dellineaceae, is a woody climber distributed in India, Sri Lanka, China, Laos, Cambodia, Thailand, Myanmar and Indo-Malayan archipelago. In India, it is found in the Western Ghats region of Kerala and Tamil Nadu. The root of T. akara is used by the Kani tribe of Kerala, India to cure various liver ailments like jaundice, inflammatory conditions, fever and also to enhance the immunity in children. The medicinal use of T. akara was first reported by S. Rajasekharan and his team in 1987 during Ethnobiological studies carried out with the help of Mallan Kani residing in the Chonnampara tribal settlement of Thiruvananthapuram district, Kerala (Saradamma et al., 1994). Leaf decoction of T. akara is used to treat pulmonary haemorrhages and gargles for aphthae (Udayan et al., 2009). T. akara contains terpenoids like Betulin, Betulinic acid, Lupeol and $\beta$-Sitosterol, which has a wide range of bioactivities like anti-HIV, anti-diabetic and anti-inflammatory (Lima et al., 2014). The objectives of the present study are to compare the in vitro free radical scavenging properties of different solvent extracts of the roots of T. akara (Burm. f.) Merr. an ethno-medicinal plant used by the Kani tribe and to estimate the total phenolic, flavonoid and condensed tannin contents.

\section{Materials and Methods:-}

\section{Chemical reagents:-}

The solvents used were of HPLC grade. All the standards like Ascorbic acid, Gallic acid, Quercetin, Catechin etc. and chemicals like Aluminium chloride, Potassium acetate, Sodium carbonate, 1,1-diphenyl-2-picryl hydrazyl (DPPH), Sodium nitroprusside, nitroblue tetrazolium (NBT), Phenazine methosulfate (PMS) were obtained from Sigma Aldrich, USA. Folin-Ciocalteu reagent, Vanillin reagent, Griess reagent etc. was purchased from Hi Media, Mumbai, India.

\section{Collection and authentication of plant material:-}

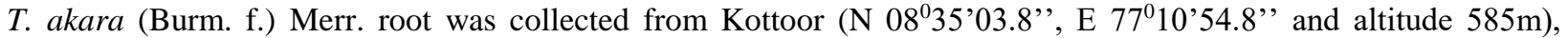
Thiruvananthapuram district of Kerala, India and authenticated by the plant taxonomist of the JNTBGRI, Palode. Voucher specimens were deposited at the Jawaharlal Nehru Tropical Botanic Garden and Research Institute Herbarium (TBGT 86868 dated $08 / 08$ /2015). The roots of the plant collected were washed in running water, shade dried, powdered and passed through 40 mesh sieve and stored in an airtight container for further use.

\section{Preparation of extracts:-}

The dried root powder weighing $100 \mathrm{~g}$ was extracted with $1000 \mathrm{ml}$ of distilled water for $48 \mathrm{~h}$ at room temperature in a shaker. After extraction, aqueous extract (TA WAT) was prepared by lyophilization. Then fresh root powder was used for serial extraction with hexane using a Soxhlet apparatus, the powder was then dried and again extracted with chloroform and finally with ethanol to get; 1 . Hexane fraction (TA HEX), 2. Chloroform fraction (TA CHL) and 3. Ethanolic fraction (TA ETH). 


\section{Quantitative phytochemical analysis:- Estimation total phenolic content:-}

The total phenolic content (TPC) was estimated according to the method of Singleton and Rossi. (1965). Briefly, 0.5 $\mathrm{mL}$ of the extract $(1 \mathrm{mg} / \mathrm{mL})$ was transferred in tubes containing $2.5 \mathrm{~mL} 10 \%$ Folin-Ciocalteu's reagent. After 10 minutes, $2 \mathrm{~mL}$ of a sodium carbonate solution $(7.5 \% \mathrm{w} / \mathrm{v})$ was added to the sample. The tubes were then allowed to stand at room temperature for $30 \mathrm{~min}$ and read absorbance at $743 \mathrm{~nm}$. The concentration of total phenols in samples was derived from a standard curve of Gallic acid ranging from 12.5 to $150 \mu \mathrm{g} / \mathrm{mL}$. The TPC was expressed as Gallic acid equivalents (GAE) in $\mu \mathrm{g} / \mathrm{mg}$ of dry extract.

\section{Estimation of total flavonoids:-}

The total flavonoid content was determined according to the aluminium chloride colorimetric method of Chang et al., (2003) with slight modification. Plant extract $(1 \mathrm{~mL}, \mathrm{mg} / \mathrm{mL})$ in methanol was mixed with $0.1 \mathrm{~mL}$ of $10 \%$ aluminium chloride hexahydrate, $0.1 \mathrm{~mL}$ of $1 \mathrm{M}$ potassium acetate and $2.8 \mathrm{~mL}$ of deionized water. After the 30 min incubation at the room temperature, the absorbance of the reaction mixture was determined spectrophotometrically at $415 \mathrm{~nm}$. Rutin was taken as a standard (the concentration range: 12.5 to $150 \mu \mathrm{g} / \mathrm{mL}$ ), the total flavonoid content was calculated from the standard curve and expressed as Rutin equivalents in $\mu \mathrm{g} / \mathrm{mg}$ of dry extract.

\section{Total condensed Tannin:-}

Condensed tannins were calorimetrically estimated by vanillin hydrochloride method by Hagerman et al., (2002). The amount of condensed tannin contents was calculated from the calibration curve of standard catechin, ranging between $50-350 \mu \mathrm{g} / \mathrm{mL}$. Tubes containing $1 \mathrm{~mL}$ each of standard/ plant extracts $(1 \mathrm{mg} / \mathrm{mL})$ in methanol were incubated at $30^{\circ} \mathrm{C}$ in a water bath and to this $5 \mathrm{~mL}$ of working reagent (mixing one part $1 \%$ vanillin with one part $8 \%$ concentrated $\mathrm{HCl}$ ) was added at an interval of $1 \mathrm{~min}$ to one set of the tubes and $5 \mathrm{~mL}$ of $4 \% \mathrm{HCl}$ was added to the other set at intervals of $1.0 \mathrm{~min}$. Kept the samples in the water bath for $20 \mathrm{~min}$ and the absorbance was read at $500 \mathrm{~nm}$. The absorbance of the blank was subtracted from that of the sample containing vanillin reagent.

\section{Antioxidant assays:-}

The antioxidant activity of the plant extracts was tested using the following methods:

\section{DPPH radical scavenging activity:-}

DPPH (1,1-diphenyl-2-picryl hydrazyl) assay has been used for the screening of different plant extracts for antioxidant activity, because it is very sensitive to the active ingredients at low concentrations. The effect of $T$. akara aqueous extract and various fractions on DPPH radicals were assayed using the standard method (Blois.1958). A methanolic solution of $2 \mathrm{~mL}$ of DPPH $(0.025 \mathrm{~g} / \mathrm{L})$ was added to $200 \mu \mathrm{L}$ of the different concentrations $(20 \mu \mathrm{g} / \mathrm{mL}$ to $320 \mu \mathrm{g} / \mathrm{mL})$ of plant extract/serial fractions and allowed to react at room temperature for $30 \mathrm{~min}$ in the dark and the absorbance was measured at $517 \mathrm{~nm}$. Methanol served as the blank and $200 \mu \mathrm{L}$ of methanol was added to DPPH in positive control tubes, instead of plant extract. Ascorbic acid was used as the standard.

\section{Nitric oxide radical scavenging assay:-}

Nitric oxide radical scavenging activity was measured using the standard procedure (Mondal et al., 2006). Nitric oxide radicals are generated from sodium nitroprusside in aqueous solution at physiological $\mathrm{pH}$ spontaneously. Nitric oxide reacts with oxygen to produce nitrite ions that can be estimated using Griess' reagent. Sodium nitroprusside ( $1 \mathrm{~mL}$ of $10 \mathrm{mM}$ ) was mixed with $1 \mathrm{~mL}$ of different concentration $(20$ to $320 \mu \mathrm{g} / \mathrm{mL})$ of plant extract/serial fractions in phosphate buffer ( $\mathrm{pH}$ 7.4). The mixture was incubated at $25^{\circ} \mathrm{C}$ for $150 \mathrm{~min}$. To $1 \mathrm{~mL}$ of the incubated solution, $1 \mathrm{~mL}$ of Griess reagent (1\% Sulphanilamide, $2 \%$ O-phosphoric acid and $1 \%$ Napthyl ethylene diamine dihydrochloride) was added. Ascorbic acid was used as standard.

\section{Superoxide radical scavenging activity:-}

The effect of superoxide radical scavenging activity was determined by the Nitroblue tetrazolium reduction method described by Fu et al., (2010). Superoxide anions are weak oxidants produced from molecular oxygen by oxidative enzymes in the biological system and also via non-enzymatic reactions. $1 \mathrm{~mL}$ of NBT solution $(156 \mu \mathrm{M}$ NBT in 100 $\mathrm{mM}$ phosphate buffer, $\mathrm{pH} 7.4), 1 \mathrm{~mL}$ of NADH solution (468 $\mu \mathrm{M}$ NADH in $100 \mathrm{mM}$ phosphate buffer, $\mathrm{pH}$ 7.4) and $0.4 \mathrm{~mL}$ of different concentrations of the plant extract/serial fractions (20 to $320 \mu \mathrm{g} / \mathrm{mL}$ ) were mixed. The reaction was started by adding $100 \mu \mathrm{L}$ of phenazine methosulphate (PMS) solution $(60 \mu \mathrm{M}$ PMS in $100 \mathrm{mM}$ phosphate buffer, $\mathrm{pH}$ 7.4) to the mixture. The reaction mixture was incubated at $25^{\circ} \mathrm{C}$ for $5 \mathrm{~min}$ and the absorbance at $560 \mathrm{~nm}$ was 
measured against blank samples, containing all the reagents except the PMS. All readings were taken in triplicate and Trolox was used as the standard.

For the above experiments the percentage radical scavenging activities of the samples were calculated using the formula:

[1 - (absorbance of sample / absorbance of control) $] \times 100$.

From the calculated radical scavenging activity, the $\mathrm{IC}_{50}$ was calculated, which represents the concentration of the scavenging compound that caused $50 \%$ neutralization.

\section{Statistical analysis:-}

The statistical significance between the samples were determined by the analysis of variance (ANOVA) and the data were recorded as mean \pm standard deviation (SD), $P=0.05$ was considered to be statistically significant. Significant differences between means were determined by Dunnett's post-test. The computer software employed for the statistical analysis was GraphPad Prism 6.01.

\section{Results and Discussion:- \\ Quantitative phytochemical analysis:-}

Polyphenols play an important role in determining antioxidant activity of a plant. Therefore, it is important to determine the total amount of phenolics in the plants. Polyphenolics including phenols, flavonoids and condensed tannin constituents are very important because of their free radical neutralizing ability and their quantification is necessary for the expression of anti-oxidant and radical scavenging capacity of a plant. The phenolic compounds act as free radical terminators (Swapna et al., 2014). The phenolic content was expressed as microgram Gallic acid equivalents per milligram dry weight ( $\mu \mathrm{g} \mathrm{GAE} / \mathrm{mg} \mathrm{DW})$ of extract and it varied significantly in different solvent extracts of the roots of T. akara. (Fig. 1). The phenolic content varied from $20.61 \pm 5.49$ to $251.17 \pm 14.04 \mu \mathrm{g} \mathrm{GAE} / \mathrm{mg}$ dry weight and the highest phenolic content was obtained in the ethanolic fraction $(251.17 \pm 14.04 \mu \mathrm{g} \mathrm{GAE} / \mathrm{mg}$ DW extract) of $T$. akara roots. Phenolic compounds are the wide spread natural compounds with multiple hydroxyl groups present in plants and plays an important role in free radical scavenging by acting as hydrogen donators or metal chelators or singlet oxygen quenchers (Kessler et al., 2003). They have a potential of combating oxidative stress syndrome responsible for some neurodegenerative diseases and cardiovascular diseases. The mechanism of action of flavonoid is through scavenging or chelating process and the scavenging of oxygen derived free radicals is an important property, thus making them a natural antioxidant (Cook et al., 1996). The highest flavonoid content was estimated in the ethanolic fraction of root $(94.52 \pm 7.11 \mu \mathrm{g} \mathrm{QE} / \mathrm{mg} \mathrm{DW}$ extract) of $T$. akara. The aqueous extract also possesses a considerable amount of flavonoids, which is $73.22 \pm 5.23 \mu \mathrm{g} \mathrm{QE} / \mathrm{mg}$ DW (Fig. 1). Flavonoids are polyphenolic compounds abundantly present in food and medicinal plants as glycosides. They contain many phenolic hydroxyl groups helping in scavenging the reactive oxygen species and stabilizing lipid oxidation (Yen et al., 1993). The condensed tannins in the plant source can act as primary antioxidants and free radical inhibitors by reacting with free radicals (Chung et al., 1998). Condensed tannins (or proanthocyanidins) comprise of a group of polyhydroxy flavan-3-ol oligomers and polymers linked by carbon-carbon bonds between flavanol subunits. The most widely distributed condensed tannin in the plant tissues is procyanidins, which derived from catechin or epicatechin and may contain Gallic acid esters (Wong et al., 2006). The reactivity of condensed tannin with molecules of biological significance has important nutritional and physiological consequences (Sulaiman et al., 2011). The estimation of condensed tannin from different solvent extracts of T. akara root showed that the aqueous extract represented higher condensed tannin content (65.88 $\pm 5.53 \mu \mathrm{g} \mathrm{CE} / \mathrm{mg}$ DW extract). The ethanolic and chloroform fractions contain 47.95 \pm 3.58 and $17.11 \pm 2.9 \mu \mathrm{g} \mathrm{CE} / \mathrm{mg}$ DW condensed tannin respectively (Fig. 1). Phenolic compounds, such as flavonoids, phenolic acid and tannins possess anti-inflammatory, anti-carcinogenic, anti-atherosclerotic and other properties that may be attributed to their antioxidant activities (Osawa et al., 1994). The antioxidative activities observed can be attributed to the synergistic effects of different polyphenolic compounds in the ethanolic root extract of T. akara.

In vitro free radical scavenging activity:-

The indigenous antioxidants may be useful in preventing the deleterious consequences of oxidative stress and there is increasing interest in the protective biochemical functions of natural antioxidants contained in herbs and medicinal plants (Nagulendran et al., 2007). There are different experimental methods to evaluate free radical scavenging activity of a plant extract or product and one such method is evaluating the ability of plant extract to scavenge of DPPH radicals. DPPH is a stable nitrogen centered, purple coloured free radical and when it encounters a proton donating substance, it would be scavenged and the absorbance is reduced. Because of its odd electron, DPPH gives a strong 
absorption maximum at $517 \mathrm{~nm}$ by visible spectroscopy (purple colour). As the odd electron of the radical becomes paired off in the presence of a hydrogen donor, the absorption strength is decreased and the resulting decolorisation is stoichiometric with respect to the number of electrons captured. In DPPH radical scavenging assay aqueous extract along with hexane, chloroform and ethanol fractions exhibited significant $(P=0.05)$ radical scavenging potential in a concentration dependent manner (Fig. 2). The ethanolic fraction at $320 \mu \mathrm{g} / \mathrm{ml}$ showed the maximum percentage of radical (86.14\%) inhibition and $\mathrm{IC}_{50}$ value was $22.06 \mu \mathrm{g} / \mathrm{mL}$ which is comparable to the ascorbic acid standard with $\mathrm{IC}_{50}$ value of $13.32 \mu \mathrm{g} / \mathrm{mL}$. The $\mathrm{IC}_{50}$ values of aqueous extract and chloroform fraction are calculated from the standard graph and were found to be 29.95 and $780 \mu \mathrm{g} / \mathrm{mL}$ respectively. The polyphenolic compounds like phenols and flavonoids present in the plant extract can act as strong proton donors and this is attributed to the potent DPPH radical scavenging activity of T. akara. Nitric oxides are molecules containing unpaired electron generated in biological systems by NADPH dependent nitric oxide synthases. They act as important oxidative biological signaling molecule in a variety of physiological processes such as regulation of blood pressure and immune response, smooth muscle relaxation and neural signal transmission (Harput et al., 2011). Overproduction of NO may occur when the generation of nitrogen species supersedes the ability of the biological system to neutralize and eliminate them. In this assay, nitric oxide is generated spontaneously from sodium nitroprusside (SNP) in aqueous solution at physiological pH (7.2). Under aerobic conditions, nitric oxide reacts with oxygen to generate nitrate and nitrite products, the quantity of which can be estimated by using Griess reagent. Here Fig. 3 shows the concentration depended response curve of nitric oxide radical scavenging activity of different solvent extracts of $T$. akara. The ethanolic fraction shows highest nitric oxide radical activity with an $\mathrm{IC}_{50} \mathrm{value}$ of $50.04 \mu \mathrm{g} / \mathrm{mL}$ followed by aqueous extract with an $\mathrm{IC}_{50}$ of $62.82 \mu \mathrm{g} / \mathrm{mL}$. These values obtained were significant when compared to standard ascorbic acid with an $\mathrm{IC}_{50}$ value of $26.03 \mu \mathrm{g} / \mathrm{ml}$. The hexane and chloroform fractions showed less nitric oxide scavenging activity when compared to the other two. In the present study, the reduction of nitrate and nitrite products generated in the reaction mixture might be due to the competition of antioxidant molecules present in the extracts with oxygen to react with nitric oxide, which ultimately leads to the inhibition of nitrite ions. Superoxide anion radical is one of the strongest ROS among the free radicals and get converted to other harmful reactive oxygen species such as hydrogen peroxide and hydroxyl radical causing damages to biomolecules. They induce oxidative damage in lipids, protein and DNA by producing powerful and dangerous hydroxyl radicals, hydrogen peroxide, peroxy nitrite and singlet oxygen ultimately (Al-Mamun et al., 2007). Here superoxide radicals are generated in PMS-NADH systems by oxidation of NADH and assayed by the reduction of nitro-bluetetrazolium $(\mathrm{NBT})$, measured at $560 \mathrm{~nm}$. The superoxide radicals produced in the reaction mixture were scavenged by the extracts in a concentration dependent manner. The highest inhibition of superoxide radicals was $88.56 \%$ observed in ethanolic fraction at $320 \mu \mathrm{g} / \mathrm{ml}$. The comparative radical activities of various solvent extracts were shown in Fig. 4. The $\mathrm{IC}_{50}$ value for the same was obtained as $36.45 \mu \mathrm{g} / \mathrm{mL}$ which is comparable to standard ascorbic acid with an $\mathrm{IC}_{50}$ of $24.58 \mu \mathrm{g} / \mathrm{mL}$. The probable mechanism leading to the superoxide radical scavenging activity may be due to the inhibitory effect of the antioxidants in the extracts towards the generation of superoxide in the reaction mixture. In the study the comparative quantitative polyphenolic estimation of various solvent extracts of root of $T$. akara showed that the ethanolic fraction is rich in phenol, flavonoid and tannin when compared to other solvent extracts taken. A direct co-relation can be seen between the total polyphenolic estimation and antioxidant capacity of the extract as in all the three-free radical scavenging assays and the ethanolic extract showed potent activity in a concentration dependent manner. The $\mathrm{IC}_{50}$ values of ethanolic fraction of $T$. akara for the radical scavenging assays were comparable to the standard Ascorbic acid (Table.1). Preliminary phytochemical analysis revealed the presence of bioactive phytoconstituents like flavonoids, phenols, tannins, saponins and terpenoids in the crude extract and ethanolic fraction of $T$. akara root (Ragesh et al., 2016). This fact suggests that free radical scavenging activity of the studied extracts is mainly due to the polyphenolic compounds present in it.

\section{Conclusion:-}

From the investigations, it was evident that the free radical scavenging of the plant extracts can be attributed to the presence of polyphenolic compounds. The root of T. akara exhibited significant antioxidant and free radical scavenging activity which substantiates various traditional medicinal uses of the plant and becomes the base for the scientific validation of the tribal claim. Further studies are underway to isolate the bioactive compounds responsible for the multiple therapeutic effect of the plant. Obtained data will be employed as a basis for selection of this plant with high antioxidant potential for the preparation of cost effective herbal medicines with least side effects. 


\section{Acknowledgements:-}

The authors would like to thank Department of Science and Technology (DST- INSPIRE), India for financial assistance and The Director, Jawaharlal Nehru Tropical Botanic Garden and Research Institute, Palode for the providing necessary facilities.

\section{Conflict of Interest:-}

The authors have no conflict of interest.

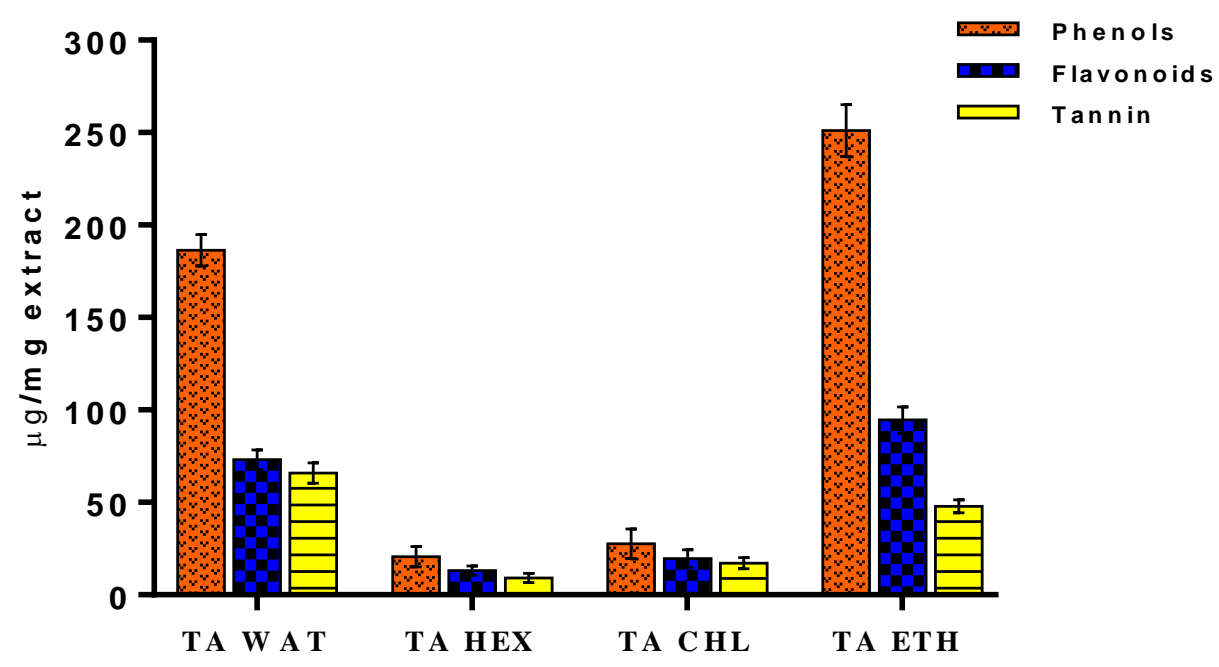

Figure 1:- Total phenolic content ( $\mu \mathrm{g}$ GAE/mg DW extract), total flavonoid content ( $\mu \mathrm{g}$ QE/mg DW extract) and condensed tannin content ( $\mu \mathrm{g} \mathrm{CE} / \mathrm{mg}$ DW extract) in aqueous and different fractions of Tetracera akara root. Values are the mean $\pm \mathrm{SD}, \mathrm{n}=3$ in each group, analysis of variance (ANOVA) followed by Dunnett's post-test.

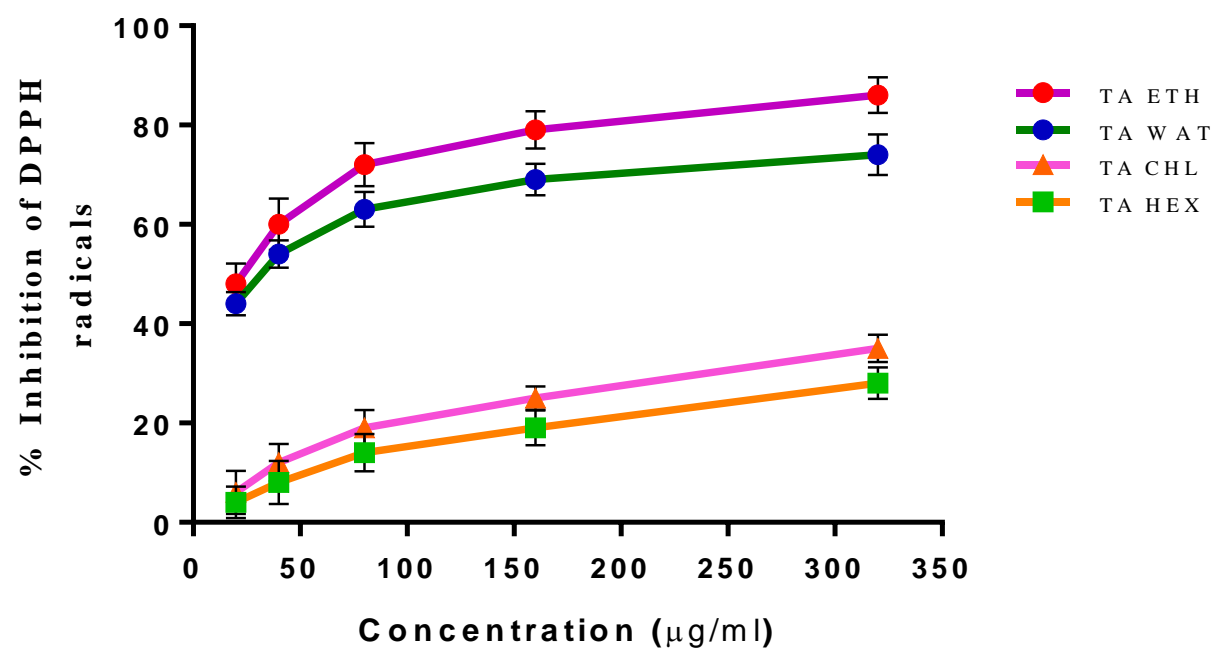

Figure 2:- The free radical scavenging effect of different solvent extracts of Tetracera akara root against DPPH (1,1diphenyl-2-picryl hydrazyl) radicals in vitro. Values are the mean $\pm \mathrm{SD}, \mathrm{n}=3$ in each group, analysis of variance (ANOVA) followed by followed by Dunnett's post-test. 


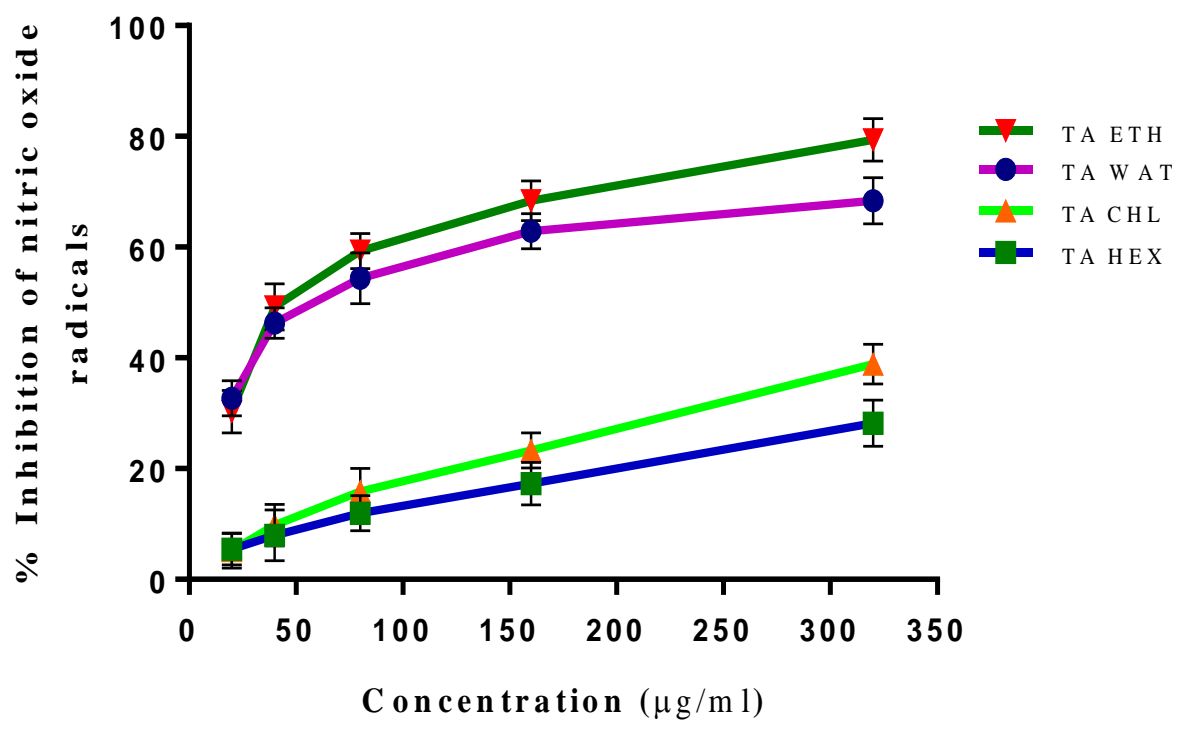

Figure 3:- The free radical scavenging effect of different solvent extracts of Tetracera akara root against nitric oxide radicals in vitro. Values are the mean $\pm \mathrm{SD}, \mathrm{n}=3$ in each group, analysis of variance (ANOVA) followed by followed by Dunnett's post-test.

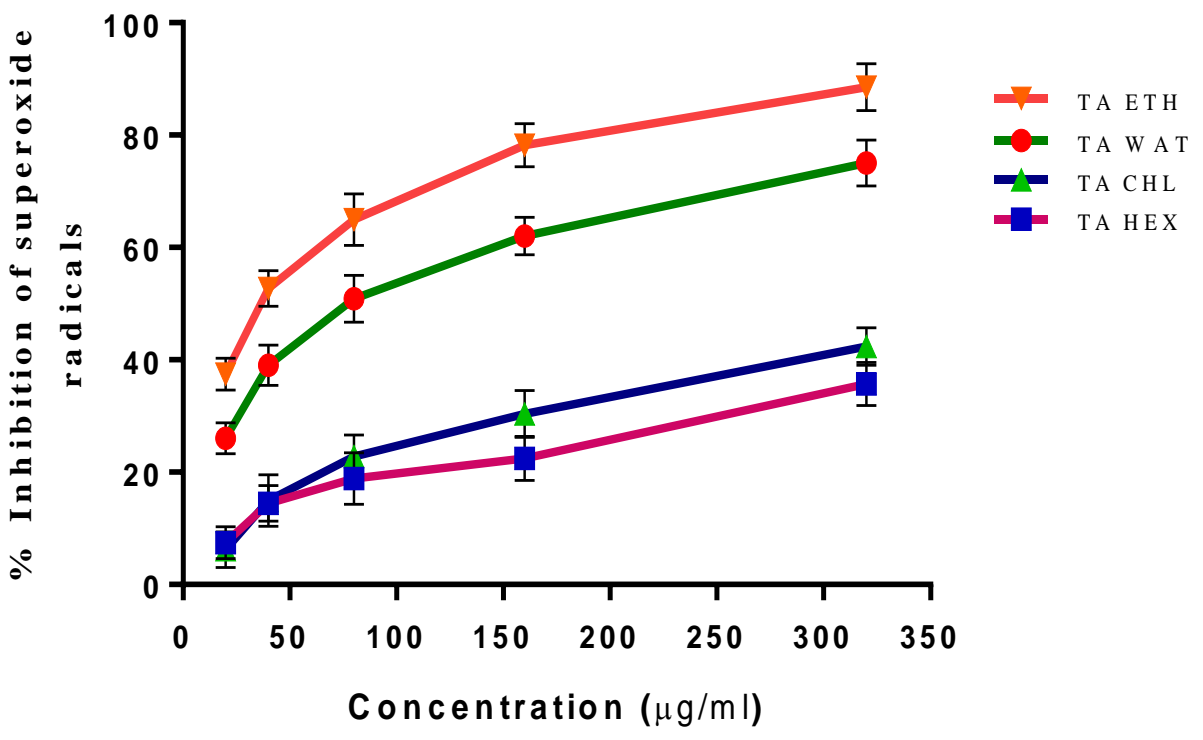

Figure 4:- The free radical scavenging effect of different solvent extracts of Tetracera akara root against superoxide radicals in vitro. Values are the mean $\pm \mathrm{SD}, \mathrm{n}=3$ in each group, analysis of variance (ANOVA) followed by followed by Dunnett's post-test. 
Table 1:- Comparative $\mathrm{IC}_{50}$ values of free radical scavenging assays of different solvent extracts of Tetracera akara root against Ascorbic acid standard.

\begin{tabular}{|c|c|c|c|c|}
\hline \multirow[t]{2}{*}{ Sl. No. } & \multirow[t]{2}{*}{$\begin{array}{l}\text { T. akara various } \\
\text { solvent extract }\end{array}$} & \multicolumn{3}{|c|}{$\begin{array}{l}\mathrm{IC}_{50} \text { values for Free radical scavenging Assays } \\
\text { (in } \mu \mathrm{g} / \mathrm{mL} \text { ) }\end{array}$} \\
\hline & & $\begin{array}{c}\text { DPPH radical } \\
\text { scavenging assay }\end{array}$ & $\begin{array}{l}\text { Nitric oxide radical } \\
\text { scavenging assay }\end{array}$ & $\begin{array}{l}\text { Superoxide radical } \\
\text { scavenging assay }\end{array}$ \\
\hline 1 & $\begin{array}{c}\text { STD-AA } \\
\text { (Ascorbic acid) }\end{array}$ & $13.32 \pm 0.98$ & $25.32 \pm 1.25$ & $24.58 \pm 1.12$ \\
\hline 2 & $\begin{array}{c}\text { TA WAT } \\
\text { (Aqueous extract) }\end{array}$ & $29.95 \pm 1.35$ & $62.82 \pm 1.24$ & $77.23 \pm 1.52$ \\
\hline 3 & $\begin{array}{c}\text { TA HEX } \\
\text { (Hexane extract) }\end{array}$ & $1181.52 \pm 2.98$ & $1191.34 \pm 2.54$ & $905.7 \pm 3.02$ \\
\hline 4 & $\begin{array}{c}\text { TA CHL } \\
\text { (Chloroform extract) }\end{array}$ & $780.68 \pm 2.18$ & $588.58 \pm 1.78$ & $477.7 \pm 2.34$ \\
\hline 5 & $\begin{array}{c}\text { TA ETH } \\
\text { (Ethanolic extract) }\end{array}$ & $22.06 \pm 0.76$ & $50.04 \pm 1.08$ & $36.45 \pm 1.35$ \\
\hline
\end{tabular}

Values are the mean $\pm \mathrm{SD}, \mathrm{n}=3$ in each group, analysis of variance (ANOVA) followed by followed by Dunnett's post-test.

\section{Reference:-}

1. Al-Mamun, M., Yamak, K., Masumizu, T., Nakai, Y., Saito, K. and Sano, H. (2007). Superoxide Anion Radical Scavenging Activities of Herbs and Pastures in Northern Japan Determined Using Electron Spin Resonance Spectrometry. Int. J. Biol. Sci. 3: 349-355.

2. Blois, M. S. (1958). Antioxidant determination by the use of stable free radicals. Nature. 181, 1199-1200.

3. Blokhina, O., Virolainen, E. and Fagerstedt, K. (2003). Antioxidants, oxidative damage and oxygen deprivation stress: a review. Annals of Botany. 91: 179-194.

4. Chang, C., Yang, M., Wen, H. and Chern, J., (2002). Estimation of total flavonoid content in Propolis by two complementary colorimetric methods. J. Food Drug Analaysis. 10:178-182.

5. Chung, K. T., Wong, T. Y., Huang, Y. W. and Lin, Y. (1998). Tannins and human health: a review, Crit. Rev. Food Sci. Nutr. 38: 421-464.

6. Cook, N. C. and Samman, S. (1996). Flavonoids chemistry, metabolism, cardioprotective effects, and dietary sources. J. Nutr. Biochem. 7: 66-76.

7. Ebrahimzadeh, M. A., Nabavi. S. M., Nabavi. S. F., Eslami, B. and Ehsanifar, S. (2009). Antioxidant activity of Hyoscyamus squarrosus fruits. Pharmacologyonline. 2: 644-650.

8. Fu, W., Chen, J., Cai, Y., Lei, Y., Chen, L., Pei, L., Zhou, D., Liang, X. and Ruan, J. (2010). Antioxidant, free radical scavenging, anti-inflammatory and hepatoprotective potential of the extract from Parathelypteris nipponica (Franch. Et Sav.) Ching. J. Ethnopharmacol. 130(3), 521-528.

9. Hagerman, A. E., Riedl, K. M., Jones, G. A., Sovik, K. N., Ritchard, N. T., Hartzfeld, P. W. and Riechel, T. L. (1998). High molecular weight plant polyphenolics (tannins) as biological antioxidants. J. Agric. Food Chem. 46: 1887-1892.

10. Halliwell, B. and Gutteridge, J. M. C. (1998). Free radicals in biology and medicine. London: Oxford University Press.

11. Harput, U. S., Genç, Y., Khan, N. and Saracoglu, I. (2011). Radical scavenging effects of different Veronica Species. Records of Natural Products. 5 (2): 100-107.

12. Kessler, M., Ubeaud, G. and Jung, L. (2003). Anti and pro-oxidant activity of Rutin and Quercetin derivatives. J. Pharm. \& Pharmacol. 55: 131-142.

13. Lima, C. C., Lemos, R. P. L. and Conserva, L. M. (2014). Dilleniaceae family: an overview of its ethnomedicinal uses, biological and phytochemical profile. J. Pharmacogn. Phytochem. 3(2): 181-204. 
14. Mondal, S.K., Chakraborty, G., Gupta, M. and Mazumder, U.K. (2006). In vitro antioxidant activity of DiospyrousmalabaricaKostel bark. Ind. J. Exp. Biol. 44 (1), 39-44.

15. Nabavi, S. M., Ebrahimzadeh, M. A., Nabavi, S. F., Hamidinia, A. and Bekhradnia, A. R (2008). Determination of antioxidant activity, phenol and flavonoid content of Parrotia persica Mey. Pharmacologyonline. 2: 560-567.

16. Nagulendran, K. R., Velavan, S., Mahesh, R. and Begum, V. H. (2007). In vitro antioxidant activity of and total phenolic content of Cyperus rotundus rhizomes. E-Journal of Chemistry. 4: 440-449.

17. Osawa, T., Uritani, I., Garcia, V. V. and Mendoza, E. M. (1994) Novel neutral antioxidant for utilization in food and biological systems. Japan: Japan Scientific Societies Press; p.p 241-251.

18. Ragesh. R. Nair, Suja, S. R., Vilash, V., Aneeshkumar, A. L. and Rajasekharan. S. (2016). Pharmacognostic standardization and phytochemical analysis of Tetracera akara (Burm. f.) Merr. J. Trad. \& Folk Pra. Volume 04(2): $79-95$

19. Saradamma, L., Nair, C. R., Bhat, A. V. and Rajasekharan, S. (1994). Final technical Report - All India CoOrdinate Research Project on Ethnobiology Phase II.

20. Singleton, V.L., Rossi, J.A. (1965). Colorimetry of total phenolics with phosphor molybdic phosphor tungstic acid reagents. Am. J. Enol. Vitic. 16: 144-158.

21. Sulaiman, S., Ibrahim, D., Kassim, J., Hong, L.S. (2011). Antimicrobial and antioxidant activities of condensed tannin from Rhizophora apiculata bark, J. Chem. Pharm. Res. 3: 436-444.

22. Swapna, T. S., Archana, G. N., Mini, I. and Pradeesh, S. (2014). Free radical scavenging activity of leaves of Bidens biternata (Lour.) Merr. \& Sheriff, Int. J. of Pharm. Res. \& Dev.6: 127-135.

23. Udayan, P. S. and Indira, B. (2009). Medicinal plants of Arya Vaidya Sala Herb Garden, Dept. of Publications, Arya Vaidya Sala, Kottakal, Kerala-676503. Kottakkal Ayurveda Series.72: 345-346

24. Wong, C. C., Li, H. B., Cheng, K. W. and Chen, F. (2006). A systematic survey of antioxidant activity of 30 Chinese medicinal plants using the ferric reducing antioxidant power assay. Food Chem. 97: 705-711.

25. Yen, G. C., Duh, P. D. and Tsai, C. L. 1993. Relationship between antioxidant activity and maturity of peanut hulls. J. Agric. Food Chem. 41: 67-70. 